\title{
A Series VSI Based Voltage Sag Correcting Device with Additional VAR Compensation for Sensitive Loads
}

\author{
Student member \\ Member
}

\author{
Alper Akdă̆ \\ Susumu Tadakuma
}

(Chiba Institute of Technology)

(Chiba Institute of Technology)

\begin{abstract}
A series Voltage Source Inverter based voltage sag correcting device has been developed and tested in this paper. A control system is designed using the derived mathematical model of the sag correcting device. Voltage tracking capabilities for inner controllers and good performance characteristics for load voltage regulation and reactive power loops are demonstrated for steady state and transient conditions.

Also, additional loops for unbalanced sag conditions are designed decomposing the voltages and currents into positive and negative sequence components. Verification of the designed system has done by both simulation and experimental studies.
\end{abstract}

Keywords: Flexible AC Transmission Systems (FACTS), voltage sag, reactive power compensation, series compensation, unbalanced supply, negative and positive sequence components

\section{Introduction}

Power quality is gaining more and more attention as the number of sensitive loads used in home and industry is increasing. Power quality problems, such as harmonics, voltage unbalance, noise, outages, impulses, etc. are the main concerns of the power utility companies. These disturbances may cause loss of valuable data, interruption to communication services and long downtimes on production lines [1]. According to different surveys, about $70 \%$ of the disturbances are the voltage sags. Voltage sags generally do not cause damage to equipment, but it can easily interrupt the operation of sensitive loads. An industrial process with Adjustable Speed Drives (ASD), Programmable Logic Controllers (PLC), and/or sensitive microelectronic equipment may be shut down even for a short duration voltage sag. The interruption and restart process may take long time that causes big economical losses for the industrial companies.

Voltage sag is a reduction of $\mathrm{rms}$ voltage magnitude with a duration of $10 \mathrm{msec}$. to few seconds $[2,3]$. The possible causes for voltage sag are; i) motor starting, ii) fast re-closing of circuit breakers, and ii) remote fault somewhere on the power system. Among these three causes, faults (i.e. short circuits) have the major impact on customer's power quality [4]. If there is a fault in one of the parallel feeders, the customers connected through the other parallel feeders will be violated by the voltage sag until the corresponding circuit breaker opens. This behavior is demonstrated in the single line diagram of a typical distribution system in Fig. 1. The magnitude of the voltage sag is determined by i) how far the fault occurred from the Point of Common Coupling (PCC), ii) connection type of the transformers, iii) type of the fault (i.e. single phase fault, line-to-line fault, etc.), iv) the value of system and fault impedance. The duration depends on the operation time of the protective devices and utility's operation strategies (i.e. re-closing of circuit breakers).

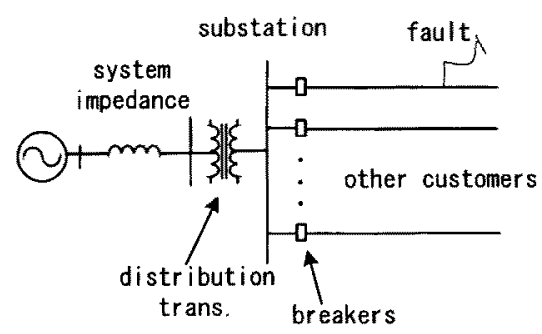

Fig. 1. Typical distribution system single line diagram

Power utilities and industrial customers themselves are taking some measures to overcome the voltage sag problems caused by faults. For the utility side, maintenance of the equipment in the power system, selection of the transformer connections at the initial installation [5] and some other measures [6] may soften the stresses caused by the voltage sags. Unpredictable causes of faults such as lightning, wind, animals, accidents by human beings, etc. and the cost of transformer replacement for changing the connection type makes these solutions inefficient.

To mitigate the voltage sag problem, industrial customers are installing power-conditioning equipment in their plants. Motor generator sets (M-G sets), uninterruptible power supplies (UPS's), ferroresonant constant voltage transformers (CVT's), magnetic synthesizers, superconducting storage devices (SSD's) are the possible solutions for providing the ride through capability to critical loads [7]. These power conditioners are relatively costly installations and the power ratings do not allow to be used with high rated loads. Use of the Voltage Source Inverters (VSI's) as a voltage sag correcting device is not new. Series and shunt connection types to the system exist in the literature [4, $8,9,10]$. References $[4,8]$ explain experimental studies of an Advanced Static VAR Compensator used as a voltage sag mitigation. In $[9,10]$, series types for the same purpose are demonstrated. 


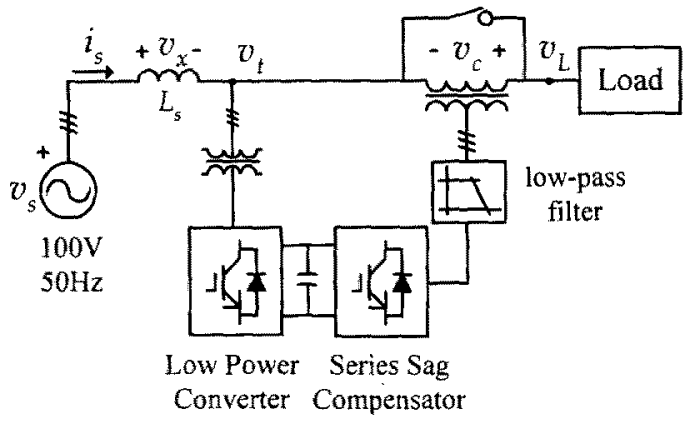

Fig.2. Single line diagram of the system

In this paper, a VSI based series type voltage sag corrector has been examined. The difference from the other systems is its capability of reactive power compensation besides the mitigation of voltage sags. This dual job of the proposed control system makes this configuration superior among the other sag correcting devices. This paper proposes the control principles and the control system for voltage sag mitigation and VAR compensation. The verification of the system has been done by simulation and experimental studies.

\section{Power Circuit Description}

The general configuration of the system equipped with a series connected sag correcting device is shown in Fig. 2. The device consists of a voltage source inverter with a filter circuit connected at its ac output terminals. The filter absorbs the voltage harmonics and outputs the desired nearly sinusoidal three phase voltages. A low power PWM converter is connected to the series device through the dc link capacitor. This shunt connected low power converter provides active power flow in both directions. The bi-directional power flow is useful for increasing the efficiency, because a small amount of active power, which goes through the series device during the compensator's operation, is fed to the power system back.

The generated three phase voltages are injected into the system through the three single-phase coupling transformers. The phase and the amplitude of the injected voltages are determined according to the reference load voltage and supply side reactive power values. During the generation of the injected voltage, following requirements should be met:

i. The amplitude (or rms value) of the load side voltage should be kept constant,

ii. The angle between the load voltage and current should be same before and after the compensation,

iii. Reactive power in the supply side should be zero.

With the use of the above requirements, the basic compensation principle is demonstrated in Fig's. 3(a) and (b). In that figure, $V_{s}$ and $I_{s}$ are the supply voltage and current respectively. $L_{s}$ is the equivalent supply inductance as seen by the bus where the series sag compensator is connected, and $V_{x}$ is the voltage drop

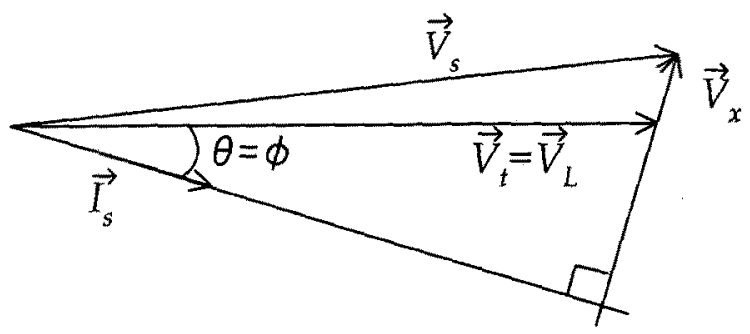

(a)

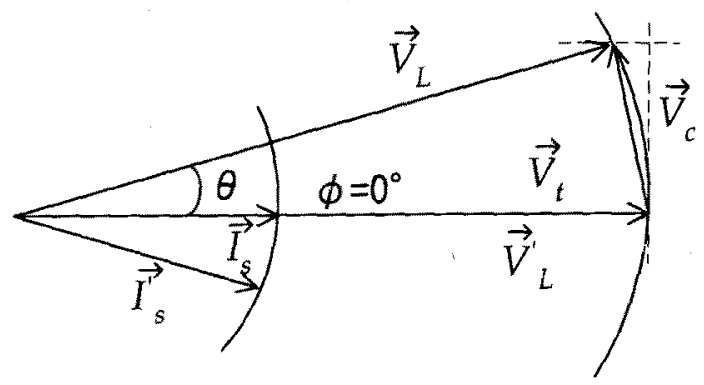

(b)

Fig. 3. Vector Diagrams

(a) before compensation (b) after compensation

across that inductance. $V_{\mathrm{T}}$ is the voltage at the Point of Common Coupling (PCC). $V_{c}$ corresponds to the secondary side.voltage of the series transformer (i.e. output of the series sag compensator), and $V_{L}$ is the voltage across the load. The vectors with prime sign (like $I_{s}, V_{L}$ ) refer to the pre-compensation values. For realizing the second and third criteria, load voltages and thus load currents, are phase shifted by the same amount so that the supply currents (or load currents, since $I_{s}=I_{L}$ ) become in phase with the $P C C$ voltages as shown in the vector diagram of Fig. 3(b). Since the injected voltage, which is in quadrature with the PCC voltage, changes the amplitude of the load side voltage, a voltage regulation loop is also needed. In order to keep the magnitude same as in the pre-compensation period, an in phase component with the PCC voltage should also be added to the output of the series device.

As expected, there is a limit for the amount of the injected series voltage. In order to determine the limits, first it is needed to obtain a mathematical expression for the injected voltage as in (1) by applying the cosine theorem in the diagram of Fig. 3(b).

$$
\begin{aligned}
& V_{c}^{2}=V_{L}^{2}+V_{L}^{2}-2 V_{L}^{2} \cos \theta \\
& V_{c}=2 V_{L} \sin \frac{\theta}{2} \ldots \ldots \ldots \ldots
\end{aligned}
$$

According to (2), the amount of the injected voltage depends on the load power factor and load voltage. A decrease in the load power factor or an increase in the load voltage will lead to an increase in the power rating of the series device. This can be seen from the active and reactive power equations that represent the powers flowing to/from the series device. 


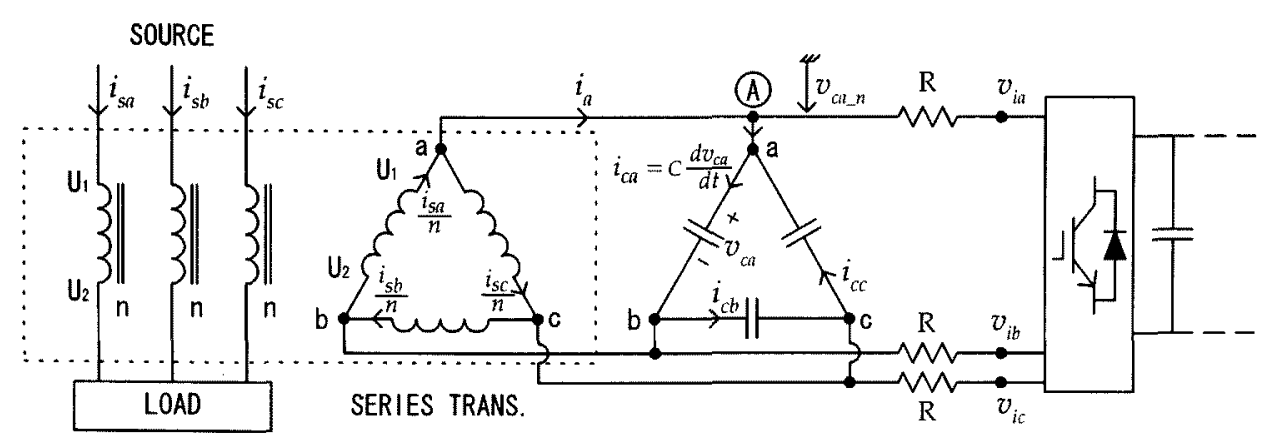

Fig. 4. Three phase representation of the voltage sag correcting device

$$
\begin{aligned}
& P_{c}=V_{c} I_{s} \sin \frac{\theta}{2} \\
& Q_{c}=V_{c} I_{s} \cos \frac{\theta}{2}
\end{aligned}
$$

Although increasing the amplitude of the injected voltage seems to be a good solution for increasing VAR compensation and voltage regulation properties, this leads to higher costs for the series inverter and shunt converter (i.e. increase in the power rating of both devices).

\section{Mathematical Description of the Corrector}

In order to obtain mathematical model of the system, three-phase representation of the single line diagram of Fig. 2 is obtained as shown in Fig. 4. Three single-phase coupling transformers are connected in delta in the inverter side, while the secondary sides are connected to each phase in series as shown. If the transformers turns ratio is $n$, the currents flowing in each phase of the delta connected primary side is equal to $i_{s(a, b, c)} / n$, where $i_{s(a, b, c)}$ represents the currents flowing through the secondary of the transformer.

Applying KCL at the point $\mathrm{A}$, the following equation can be obtained.

$$
\frac{v_{i a_{-} n}-v_{c a_{-} n}}{R}+i_{a}=i_{c a}-i_{c c}
$$

where, $i_{a}=\frac{i_{s a}}{n}-\frac{i_{s c}}{n}$

In a delta connected three-phase system, following voltage and current equations between line and phase values are well known.

$$
\begin{aligned}
& e_{Y}=\frac{e_{\Delta}}{\sqrt{3}} e^{-j \pi / 6} \\
& i_{\text {line }}=\sqrt{3} i_{\Delta_{-} p l t} e^{-j \pi / 6}
\end{aligned}
$$

Applying (6) in (5) and replacing the capacitor current by $\left(C d v_{c} / d t\right)$, (7) can be obtained.

$$
v_{i a}=\sqrt{3} e^{-j \pi / 6}\left(\frac{v_{c a}}{3}-\frac{R}{n} i_{s a}+R C \frac{d v_{c a}}{d t}\right)
$$

By rearranging ( 7 ) for a three phase representation, the voltage equations are obtained as,

$$
\left[\begin{array}{l}
v_{i a} \\
v_{i b} \\
v_{i c}
\end{array}\right]=\sqrt{3} e^{-j \pi / 6}\left(\frac{1}{3}\left[\begin{array}{l}
v_{c a} \\
v_{c b} \\
v_{c c}
\end{array}\right]+R C \frac{d}{d t}\left[\begin{array}{l}
v_{c a} \\
v_{c b} \\
v_{c c}
\end{array}\right]-\frac{R}{n}\left[\begin{array}{c}
i_{s a} \\
i_{s b} \\
i_{s c}
\end{array}\right]\right) .
$$

where $v_{i a}, v_{i b}, v_{i c}$ are the three phase output voltages of the inverter, $v_{c a}, v_{c b}, v_{c c}$ are the voltages across the capacitor, and $i_{s a}, i_{s b}, i_{s c}$ are the currents flowing through the secondary side of the series transformer.

\section{Design of the Proposed Control System}

To design a controller for the sag correcting device, as a first step, rotating axis transformation is applied to the currents and voltages. Since the sinusoidal quantities can be represented as $d c$ values at the steady state conditions by the use of this type of transformation, it is easier to decide on the controller parameters (i.e. $\mathrm{K}$ and $\tau$ for PI controllers). For that purpose, the equations in (8) are transformed into stationary frame by the transformation matrix in (9).

$$
v_{\alpha \beta}=\frac{2}{3}\left[\begin{array}{lll}
1 & e^{j 2 \pi / 3} & e^{-j 2 \pi / 3}
\end{array}\right]\left[\begin{array}{l}
v_{a} \\
v_{b} \\
v_{c}
\end{array}\right]
$$

Transformation from stationary $\alpha-\beta$ frame to rotating $d^{-} \cdot q$ frame can be obtained as follows;

$$
v_{d \eta}=e^{-j \omega t} v_{\alpha \beta}
$$

Applying (9) and (10) into (8) (see Appendix for details), the voltage equations in the rotating axis frame can be obtained as in (11) \& (12).

$$
\begin{aligned}
v_{i_{-} d}= & P_{1} v_{c_{-} d}+P_{2} v_{c_{-} q}-\sqrt{3} P_{3} i_{s_{-} d}-P_{3} i_{s_{-}} \\
& +\sqrt{3} P_{4} \frac{d}{d t} v_{c_{-} d}+P_{4} \frac{d}{d t} v_{c_{-} q} \\
v_{i_{-} q}= & -P_{2} v_{c_{-} d}+P_{1} v_{c_{-} q}+P_{3} i_{s_{-} d}-\sqrt{3} P_{3} i_{s_{-} q} \\
& -P_{4} \frac{d}{d t} v_{c_{-} d}+\sqrt{3} P_{4} \frac{d}{d t} v_{c_{-} q} \ldots \ldots \ldots
\end{aligned}
$$




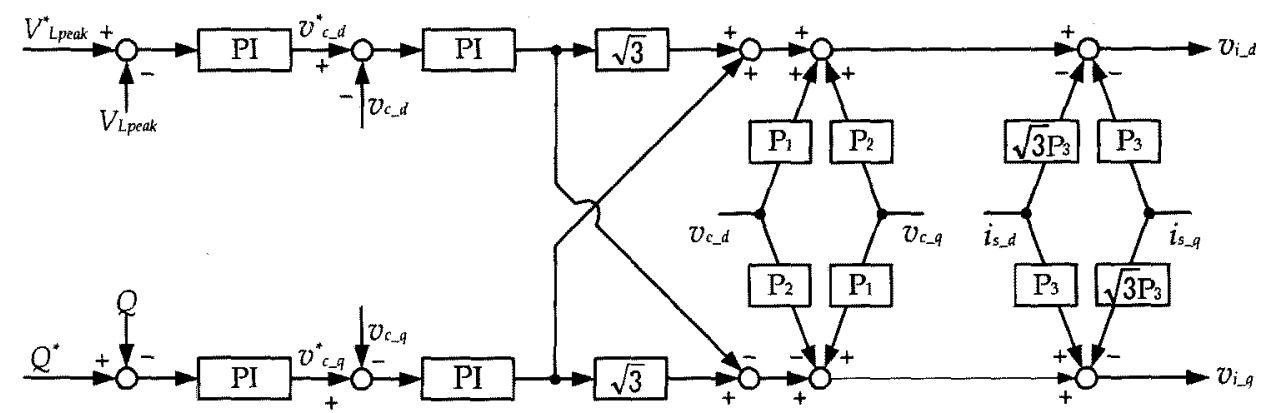

Fig. 5. Control block of the voltage sag correcting device

where, $P_{1}=\frac{1}{2}+\frac{\sqrt{3}}{2} \omega R C$

$$
P_{2}=\frac{1}{2 \sqrt{3}}-\frac{3}{2} \omega R C
$$$$
P_{3}=\frac{\sqrt{3}}{2} \frac{R}{n} \quad P_{4}=\frac{\sqrt{3}}{2} R C
$$

By rearranging (11) \& (12), the voltage equations are obtained as in (13), which is the basis of the control system for the sag correcting device.

$$
\left[\begin{array}{c}
v_{i_{-}} \\
v_{i_{-}}
\end{array}\right]=\left[\begin{array}{cccccc}
P_{1} & P_{2} & -\sqrt{3} P_{3} & -P_{3} & \sqrt{3} & 1 \\
-P_{2} & P_{1} & P_{3} & -\sqrt{3} P_{3} & -1 & \sqrt{3}
\end{array}\right]\left[\begin{array}{c}
v_{c_{-} d} \\
v_{c_{-}} \\
i_{s_{-} d} \\
i_{s_{-} q} \\
\Delta d \\
\Delta q
\end{array}\right]
$$

where

$$
\begin{aligned}
& \Delta d=(P I)\left(v_{c_{-} d}^{*}-v_{c_{-} d}\right)=k_{v d} \frac{1+\tau_{v d} s}{\tau_{v d} s}\left(v_{c_{-} d}^{*}-v_{c_{-} d}\right) \\
& \Delta q=(P I)\left(v_{c_{-} q}^{*}-v_{c_{-} q}\right)=k_{v q q} \frac{1+\tau_{v q} s}{\tau_{v q} s}\left(v_{c_{-} q}^{*}-v_{c_{-} q}\right)
\end{aligned}
$$

In (14), (PI) corresponds to Proportional-Integral control principle.

From the above derivations, it is straightforward to obtain the inner control loops for the output voltage of the series device. The basic principles of the outer loops whose outputs are used as reference values for the inner loops have been briefly explained in Section 2 . According to this, series device should be controlled as voltage regulation at the load side and reactive power compensation at the supply side principles. With the reference of the vector diagrams in Fig. 3, the q-axis component of $v_{c}$ is used to shift the load voltage in quadrature axis until $v_{t}$ and $i_{s}$ are in phase. The magnitude change of load voltage, $v_{L}$, is compensated by the proper insertion of $v_{c_{-} d}$ (i.e. d-axis component of $v_{c}$ ). This second phenomena is a voltage regulation loop that generates transient voltages during the sudden system parameter changes (e.g. a transient load side reactive power change, a voltage sag, etc.).

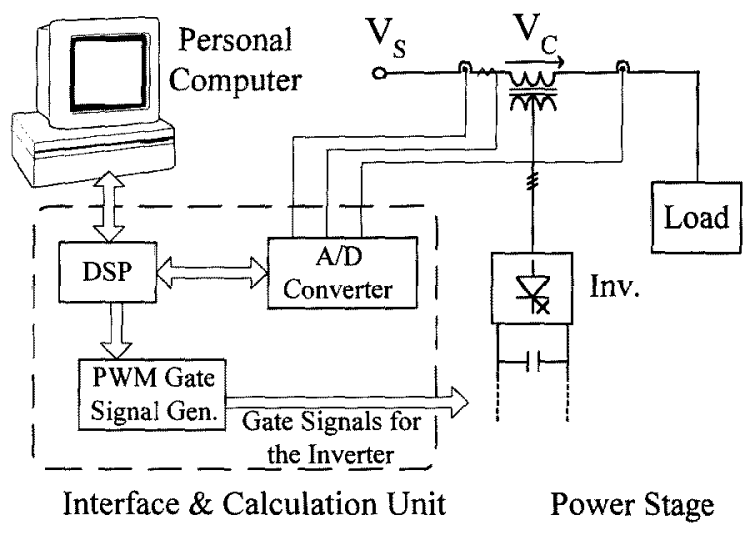

Fig. 6. Hybrid simulator for experimental studies

With the use of these main principles for the inner and outer control loops explained so far, the whole control block diagram of the sag correcting device is given in Fig. 5 including the reactive power and voltage regulation controls. $V_{\text {Lpeak }}$ and $Q$ in Fig. 5 are the peak of the load side voltage and the supply side reactive power values, respectively.

\section{Simulation and Experimental Results}

In order to observe the capability of the control system, simulation and experimental studies have been carried out. For simulation purposes, an EMTDC electromagnetic transients simulation program is used. For the experimental studies, the system has been modeled by the use of a PC based Hybrid Simulator. Experimental setup consists of three main parts as shown in Fig. 6. These are; i) physical power system, ii) interface and calculation unit, and iii) personal computer. Experimental system consists of devices which are working in digital or analog environments. In order to indicate this combination, the whole system is called as a "hybrid simulator". With this experimental setup, a C program for the proposed control system is written and compiled in the PC environment. Then the information is loaded to the "Interface \& Calculation Unit" through the parallel port of the PC. The PWM gate signals are generated according to the magnitude and phase angle information from the control system. 


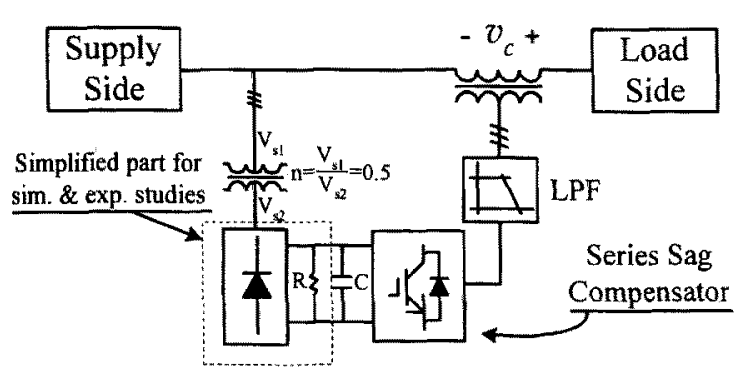

Fig. 7. Simplified experimental and simulation setup

TABle I Power and Control System Parameters for Simulation and EXPERIMENTAL StUdies

\begin{tabular}{c|c}
\hline \multicolumn{2}{c}{ Power Circuit } \\
\hline Transformer & $\begin{array}{c}2 \mathrm{kVA}, \text { three single phase } \\
200 / 100 \mathrm{~V}\end{array}$ \\
\hline Inverter & $4.2 \mathrm{kVA}$ \\
\hline Capacitance & $940 \mathrm{uF}$ \\
\hline Line Ind. & $1 \mathrm{mH}$ \\
\hline Supply Voltage & $100 \mathrm{Vrms}(1-1)$ \\
\hline 3.phase Load & $200 \mathrm{Var}, 0.87 \mathrm{pf}$ \\
\hline \multicolumn{2}{|c}{} \\
\hline \multicolumn{2}{|c}{ Control Circuit } \\
\hline$v_{c_{-} d}$ & $\mathrm{~K}=1.26 \quad \tau=1.75 \mathrm{~ms}$ \\
\hline$v_{-} q$ & $\mathrm{~K}=1.26 \quad \tau=1.75 \mathrm{~ms}$ \\
\hline$L_{- \text {peak }}$ & $\mathrm{K}=4.0 \quad \tau=5.0 \mathrm{~ms}$ \\
\hline$Q$ & $\mathrm{~K}=4.5 \quad \tau=7.5 \mathrm{~ms}$ \\
\hline
\end{tabular}

The main concern of this study is the performance and dynamics of a series sag correcting device. For that reason, any energy source (like a controllable converter, a diode rectifier or a solar cell) for the series device is acceptable, if the equivalent operating conditions are held on the dc side. A specific energy source used in the simulation and experimental studies is as shown in Fig. 7. This change does not affect the operation of the series device, and also does not cause a loss of generality, but results in simplification of the setup greatly.

5.1 Simulation Results The voltage sag correcting device has two main functions; i) voltage regulation, and ii) VAR compensation. In order to observe the capability of performing these functions and the transient response characteristics of the series device, some simulation studies have been carried out. The parameters of the power and the control systems used in the simulations are presented in Table $\mathrm{I}$.

As a first simulation study, balanced three-phase voltage sag of about $50 \%$ in the supply voltage is applied for a duration of 0.1 sec. In Fig. 8, dynamic responses can be seen for a sudden decrease in the supply side voltage, and then recovering characteristics after the end of voltage sag. Voltage drop causes a change in the reference value of $v_{c_{-} d}$. The feedback controller for $v_{c_{L} d}$ causes it to follow the reference value $\left(v_{c_{d}}^{*}\right)$ that is dictated by the $V_{L_{-} \text {peak. }}$. After the sag, $v_{c_{-} d}^{*}$ (and thus $v_{c_{-}}$) returns back to its previous value. The corrector has a fast response for correcting the sags

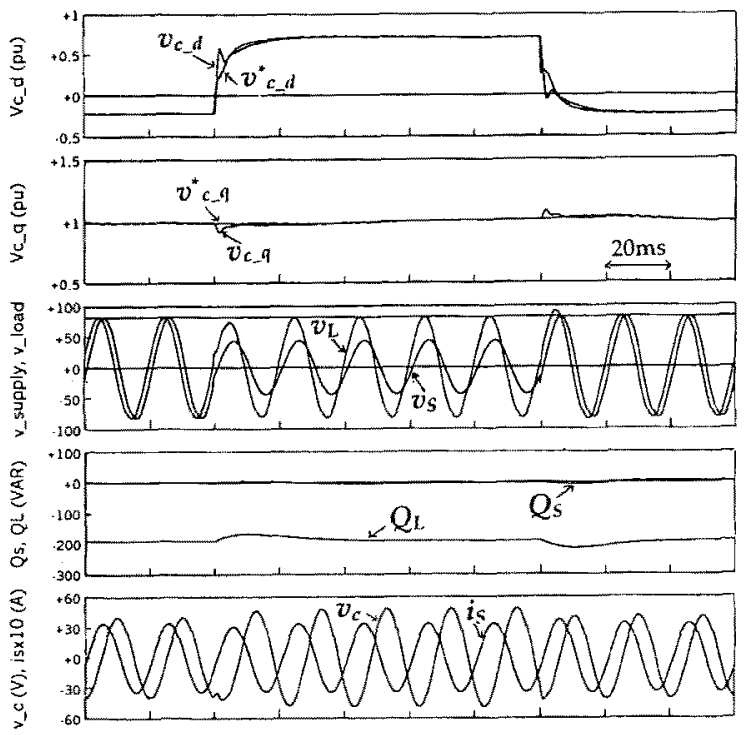

Fig. 8. Simulation results for a voltage sag of $50 \%$

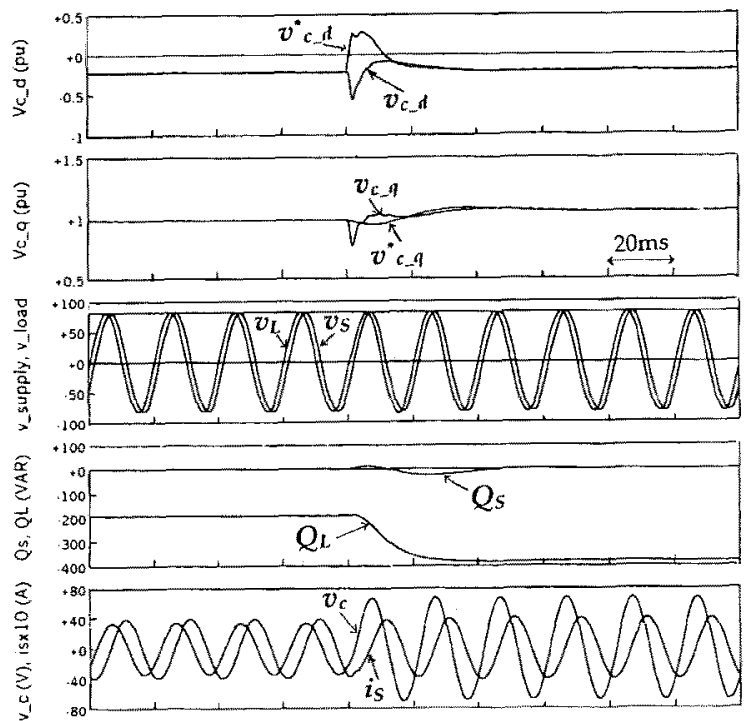

Fig. 9. Simulation results for a step change in load active and reactive power values

as can be seen from $v_{L}$ graph of Fig. 8. The load voltage returns to its pre-set value within one half cycle. Besides the sag correction, it also compensates the reactive power of the load that results in unity power factor operation as seen from the source side. In the last set of graphs of Fig. 8, one phase of the injected voltage and the current flowing through the corresponding transformer are demonstrated.

As a second simulation study, the load side active and reactive power values are doubled by a step change. The obtained results are demonstrated in Fig. 9. An increase in the load reactive power value causes a change in the reference value of the $q$ component of $v_{c}$. The controllers respond to this sudden change rapidly, and cause the system parameters to keep their pre-set values as seen from the current, voltage and power graphs of Fig. 9. 


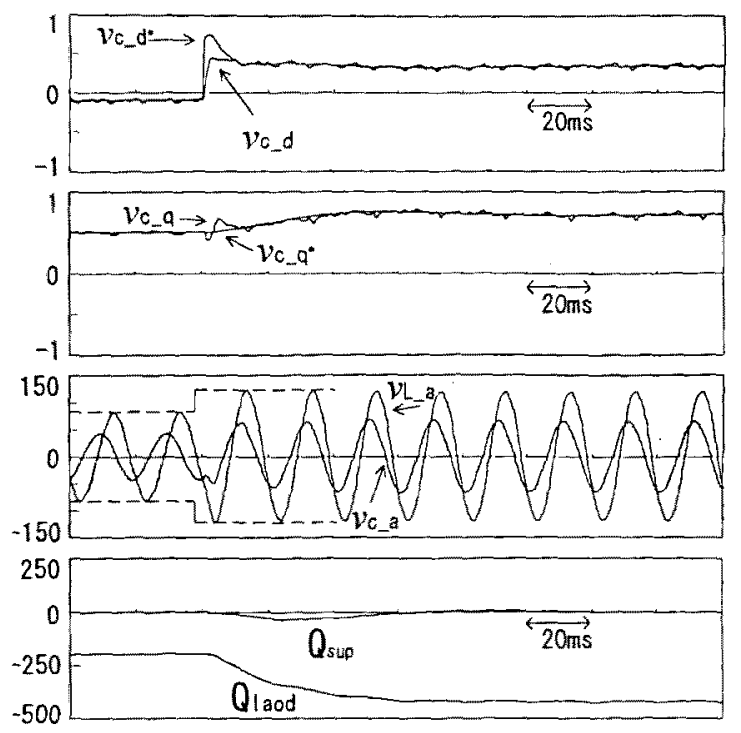

Fig.10. Experimental results for a step increase in the reference value of the load side voltage

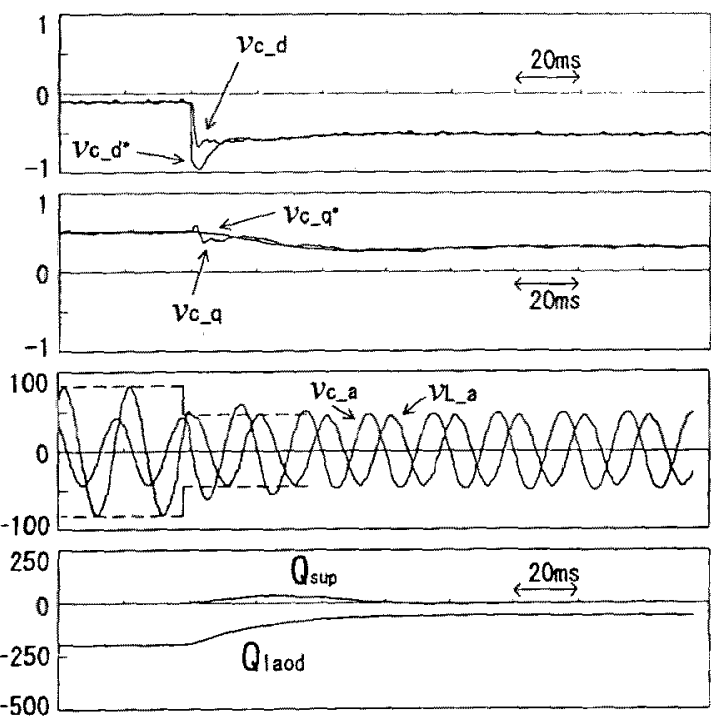

Fig.11. Experimental results for a step decrease in the reference value of the load side voltage

5.2 Experimental Results By the use of the experimental studies, the designed control system has been tested also. Since artificial sag generation is difficult and needs special equipment for demonstrating the sag correcting capability of the system, a different approach is used in the experimental studies. The experimental performance is verified by changing some of the reference values of the control system. Sudden changes in the reference value of the load voltage amplitude give us a general idea about how the sag correcting device responds in some sag conditions. For that purpose, the following four test cases are applied during the experimental studies.

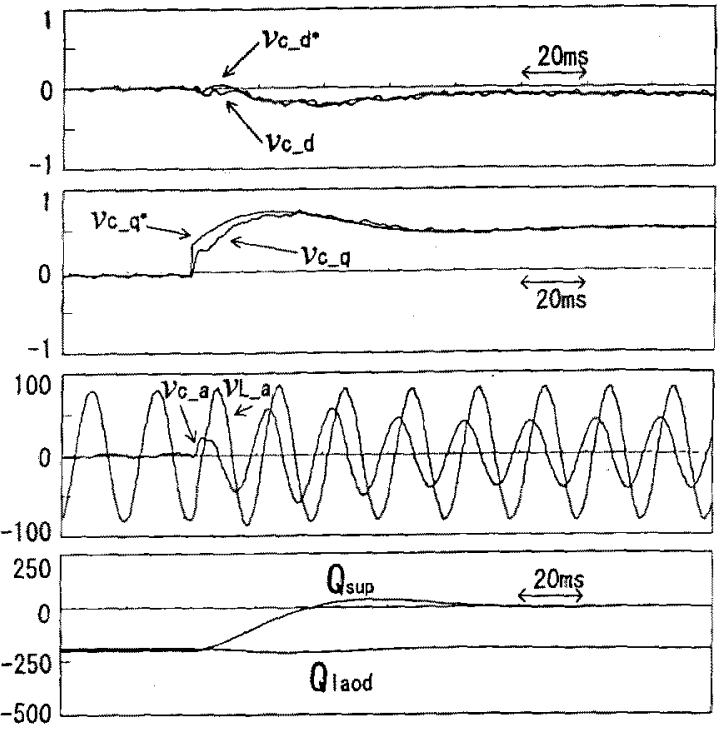

Fig.12. Experimental results for a supply side reactive power reference change from $(-200 \mathrm{VAR})$ to 0

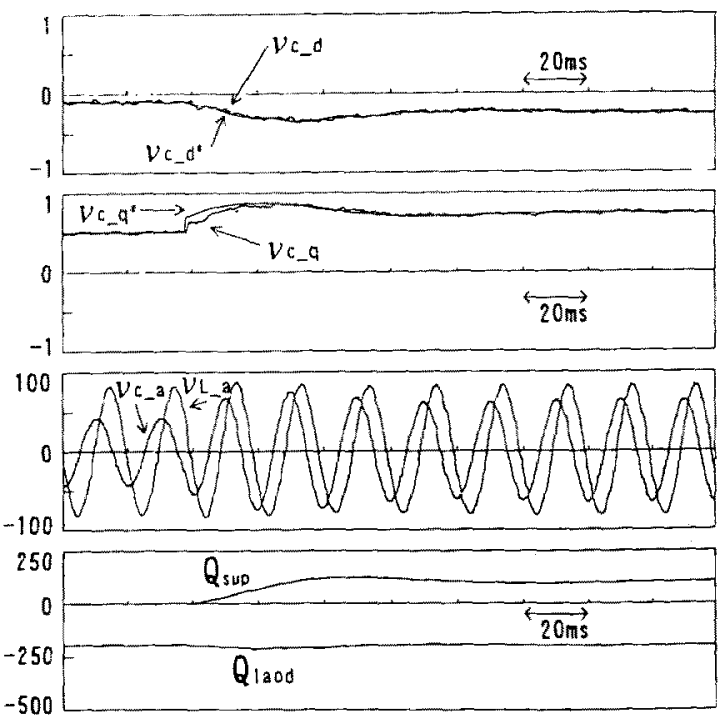

Fig.13. Experimental results for a supply side reactive power reference change from 0 to (100VAR)

i) a step increase of $50 \%$ in the reference value of the load side voltage,

ii) a step decrease of $50 \%$ in the reference value of the load side voltage,

iii) supply side reactive power reference change from $(-200 \mathrm{VAR})$ to 0 ,

iv) supply side reactive power reference change from 0 to (100VAR).

For each case, the obtained experimental results are demonstrated in Figs. 10, 11, 12 and 13 respectively. From the examination of the experimental results, controllers of the inner loops (for $v_{c_{-} d}, v_{c_{-}}$) and the outer loops (for $V_{\text {Lpeak }}$ and $Q$ ) operate satisfactorily both in the steady state and dynamic conditions. 


\section{Modification of the Control System for Unbalanced Voltage Sags}

As explained above, the main cause of the voltage sags is the faults occurred somewhere in the power system. The distance of the fault from the other customers or the type of the fault (line-to-ground, line-to-line, etc.) causes different kinds of voltage sags. As expected, three-phase balanced voltage drops are not the only type that can occur. The number of the sags that causes unbalanced drops in each phase is not negligible. For that reason, in this section, the modification of the control system of the sag correcting device for such kind of voltage sags will be briefly described and the simulation results will be demonstrated.

The voltage sags that cause an unbalance in the input voltage of an industrial load will result in negative sequence components, besides the usual positive sequence components. Addition to the control system, certainly, should eliminate these negative sequence components to minimize the undesirable effects.

For the design of additional loops, decomposition of the electrical variables, such as currents and voltages, into the negative and positive sequence components is needed. In this study, the decomposition is done in the stationary reference frame. Basic principle of the method used, is demonstrated in (15) and (16) [11]

$$
\begin{aligned}
& {\left[\begin{array}{l}
i_{\alpha}^{n} \\
i_{\beta}^{n}
\end{array}\right]=\frac{1}{2}\left[\begin{array}{c}
i_{\alpha}-j i_{\beta} \\
i_{\beta}+j i_{\alpha}
\end{array}\right]} \\
& {\left[\begin{array}{l}
i_{\alpha}^{p} \\
i_{\beta}^{p}
\end{array}\right]=\left[\begin{array}{c}
i_{\alpha} \\
i_{\beta}
\end{array}\right]-\left[\begin{array}{l}
i_{\alpha}^{n} \\
i_{\beta}^{n}
\end{array}\right]}
\end{aligned}
$$

where $i_{\alpha}$ and $i_{\beta}$ are the values obtained by stationary axis transformation of any three phase currents in the system and the variables with superscript " $p$ " and " $n$ " refer to values which are decomposed to their positive and negative sequences. Same idea is also applicable to the decomposition of the voltages into their positive and negative sequence components.

This decomposition principle is chosen instead of using the decomposition technique in $\mathrm{d} \cdot \mathrm{q}$ synchronously rotating frame. In the latter one, oscillating signals with double fundamental frequency are generated in addition to the formal dc values of the transformed $d \cdot q$ components in negative and positive synchronously rotating frames. These ac signals should be eliminated by using low-pass or notch filters [12]. But the method used in this paper does not need any filter for obtaining the quantities in negative and positive synchronous frames. The absence of filters makes this controller faster and avoids the possible instability problems.

Synchronously rotating frame transformation for negative sequence of any voltage signal can be obtained by using (17).

$$
v_{d q}^{n}=e^{j \omega t} v_{\alpha \beta}^{n}
$$

Applying the above transformation equations to three-phase currents and voltages, and arranging the resulted equations according to the PI control principle, the following equations are obtained.

$$
\left[\begin{array}{c}
v_{i_{-}}^{n} d \\
v_{i_{-}}^{n}
\end{array}\right]=\left[\begin{array}{cccccc}
N_{1} & N_{2} & -\sqrt{3} N_{3} & -N_{3} & \sqrt{3} & 1 \\
-N_{2} & N_{1} & N_{3} & -\sqrt{3} N_{3} & -1 & \sqrt{3}
\end{array}\right]\left[\begin{array}{c}
v_{c_{-} d}^{n} \\
v_{c_{-}}^{n} \\
i_{s_{-} d}^{n} \\
i_{s_{-}}^{n} \\
\Delta d \\
\Delta q
\end{array}\right]
$$

$$
\begin{aligned}
& \text { where } N_{1}=\frac{1}{2}-\frac{\sqrt{3}}{2} \omega R C \quad N_{2}=\frac{1}{2 \sqrt{3}}+\frac{3}{2} \omega R C \\
& N_{3}=\frac{\sqrt{3}}{2} \frac{R}{n} \quad N_{4}=\frac{\sqrt{3}}{2} R C \\
& \Delta d=(P I)\left(v_{c_{-} d}^{n "}-v_{c_{-} d}^{n}\right)=k_{v d} \frac{1+\tau_{v d} s}{\tau_{v d} s}\left(v_{c_{-} d}^{n{ }^{*}}-v_{c_{-} d t}^{n}\right) \\
& \Delta q=(P I)\left(v_{c_{-} q}^{n^{*}}-v_{c_{-} q}^{n}\right)=k_{v q} \frac{1+\tau_{v q} s}{\tau_{v q} s}\left(v_{c_{m i q}}^{n}{ }^{*} v_{c_{-} q}^{n}\right)
\end{aligned}
$$

It should be noted that the superscript " $n$ " is used to denote the negative sequence components. The subscripts " $d$ " and " $q$ " refers the $d$-axis and $q$-axis components of the variables in the synchronously rotating frame.

The injected positive sequence components do the usual job of the corrector (i.e. sag correction and VAR compensation), while the negative sequence components are generated according to the unbalance factor of the supply voltage. The inverse transformation from $d \cdot q$ to $\alpha-\beta$ can be obtained as in (19).

$$
\left[\begin{array}{l}
v_{i \alpha} \\
v_{i \beta}
\end{array}\right]=\left[\begin{array}{cccc}
\cos (\omega t) & -\sin (\omega t) & \cos (\omega t) & \sin (\omega t) \\
\sin (\omega t) & \cos (\omega t) & -\sin (\omega t) & \cos (\omega t)
\end{array}\right]\left[\begin{array}{c}
v_{i d}^{p} \\
v_{i q}^{p} \\
v_{i d}^{n} \\
v_{i q}^{n}
\end{array}\right]
$$

Two simulation studies have been performed for the investigation of the compensator's performance in unbalanced supply conditions. First case is an unbalance voltage drop simulation for each phase (i.e. $a \rightarrow \% 80, b \rightarrow \% 70, c \rightarrow \% 60$ of their nominal values). In Fig. 14, the obtained results are demonstrated. As can be seen from these diagrams, the additional loops (i.e. negative sequence elimination loops) work properly to balance the line-to-line voltage at the load terminals where the line supply voltages are unbalanced and lower in magnitude according to their nominal values. 


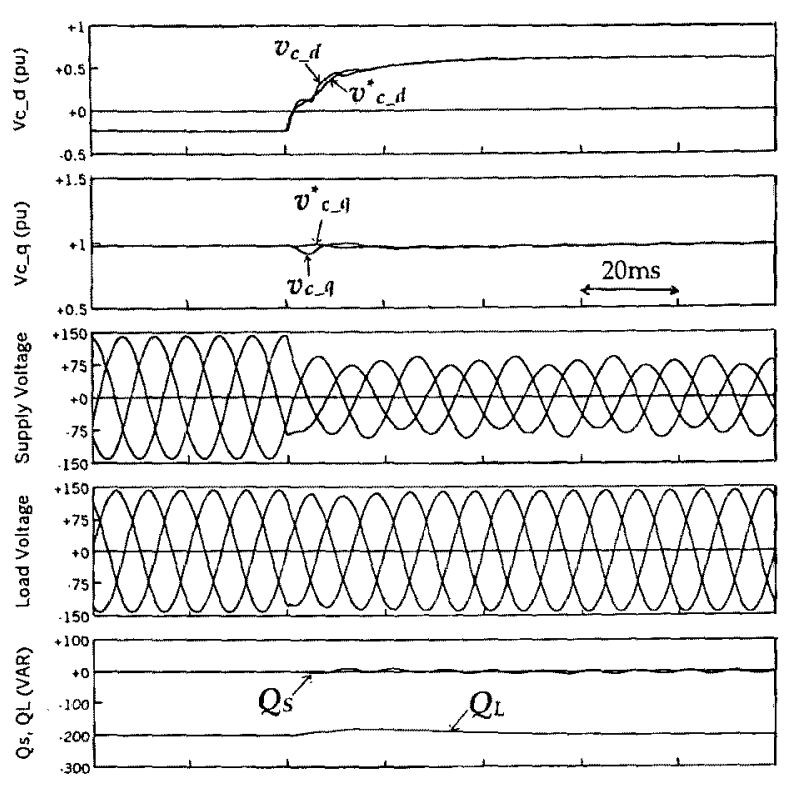

Fig. 14 Simulation result for an unbalanced voltage sag in the supply voltage

The second simulation is a step change in the load active and reactive powers $(P \rightarrow 2 P, Q \rightarrow 2 Q)$ while unbalanced sag exists in the supply system. As can be seen from the results demonstrated in Fig. 15, the system has the ability to respond quickly to compensate the reactive power changes also, even for the unbalanced supply voltage condition.

\section{Conclusion}

In this paper, a sag correcting device with additional VAR compensation has been demonstrated for different voltage sag and load conditions. With the experimental and simulation studies, it has been shown that this series device is an efficient tool for correcting both the balanced and unbalanced voltage sags. Additional VAR compensation property is an extra benefit, which makes this system superior to other voltage sag correcting devices.

The controller is designed in the $d \cdot q$ frame and it allows an effective voltage regulation and power factor correction. It has been observed that series device responds very fast under sudden power system or load parameters changes, reaching its steady state in less than one cycle of fundamental.

\section{Acknowledgement}

The authors would like to thank $\mathrm{Mr}$. Tsutomu Yamaguchi for his assistance with the experimental studies. Also, one of the authors, Alper Akdag, acknowledges Japanese Government for providing the Monbusho scholarship during his stay in Japan.

(Manuscript received June 5, 2000, revised Nov. 20, 2000)

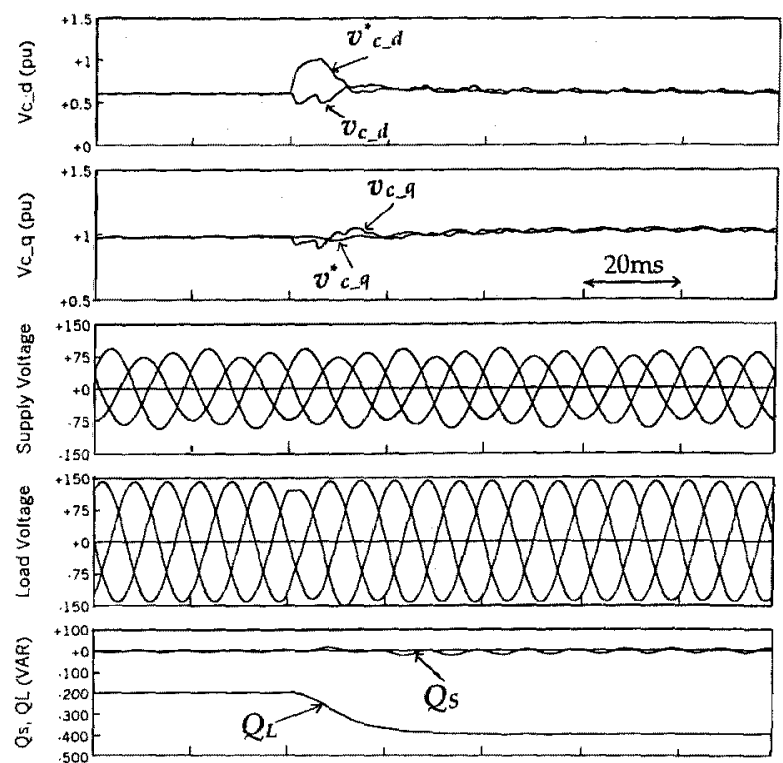

Fig. 15 Simulation result for a step change in load reactive power while the sag in the supply side is continuing

\section{References}

1. V. Bhavaraju, P. Enjeti, "A Fast Active Power Filter to Correct Line Voltage Sags," IEEE Trans. on Industrial Electronics, Vol. 41, No. 3, pp. 333-338, June 1994

2. G. Yalcinkaya, H. J. Bollen, P. A. Crossley, "Characterization of Voltage Sags in Industrial Distribution Systems," IEEE Trans. on Industry Applications, Vol. 34, No. 4, pp. 682.688, July/Aug. 1998

3. B. M. Hughes, J. S. Chan, D. O. Koval, "Distribution Customer Power Quality Experience," IEEE Trans. on Industry Applications, Vol. 29, No. 6, pp. 1204-1211, Nov./Dec. 1993

4. P. Wang, N. Jenkins, M H. J. Bollen, "Experimental Investigation of Voltage Sag Mitigation by an Advanced Static VAR Compensator," IEEE Trans. on Power Delivery, Vol. 13, No. 4, pp. 1461-1467, October 1998

5. C. Becker, W. Braun, K. Carrick, T. Diliberti, C. Grigg, J. Goesch, B. Hazen, T. Imel, D. Koval, D. Mueller, T. St. John, L. Conrad, "Proposed Chapter 9 for Predicting Voltage Sags (Dips) in Revision to IEEE Std 493, the Gold Book," IEEE Trans. on Industry Applications, Vol. 30, No. 3, pp. 805-821, May/June 1994

6. C. J. Melhorn, T. D. Davis, G. E. Beam, "Voltage Sags: Their Impact on the Utility and Industrial Customers," IEEE Trans. on Industry Applications, Vol. 34, No. 3, pp. 549-558, May/June 1998

7. J. Lamoree, D. Mueller, P.Vinett, W. Jones, M. Samotyj, "Voltage Sag Analysis Case Studies," IEEE Trans. on Industry Applications, Vol. 30, No. 4, pp. 1083-1089, July/Aug. 1994

8. A. V. Zyl, J. Enslin, R. Spee, "Converter-Based Solution to Power Quality Problems on Radial Distribution Lines," IEEE Trans, on Industry Applications, Vol. 32, No. 6, pp. 1323-1330, Nov./Dec. 1996

9. D.T. Heydt, W. Tan, T. LaRose, M. Negley, "Simulation and Analysis of Series Voltage Boost Technology for Power Quality Enhancement," IEEE Trans. on Power Delivery, Vol. 13, No. 4, pp. 1335-1341, October 1998 
10. S. W. Middlekauff, E. R. Collins, "System and Customer Impact: Considerations for Series Custom Power Devices," IEEE Trans. on Power Delivery, Vol. 13, No. 1 , pp. 278-282, January 1998

11. A. Akdag, S. Tadakuma, H. Minakata, "Load Balancing Control by Symmetrical Coordinates Frame for PWM Inverter Based Reactive Power Compensators," The Transactions of IEE Japan, Vol. 121-D, No. 1, pp.43-51, January 2001

12. H. Song, K. Nam, "Dual Current Control Scheme for -PWM Converter Under Unbalanced Input Voltage Conditions," IEEE Trans. on Industrial Electronics, Vol. 46, No. 5, pp. 953-959, October 1999

\section{Appendix}

$$
v_{i \alpha \beta}=\frac{2}{3}\left[\begin{array}{lll}
1 & e^{j 2 \pi / 3} & e^{-j 2 \pi / 3}
\end{array}\right]\left[\begin{array}{l}
v_{i a} \\
v_{i b} \\
v_{i c}
\end{array}\right]
$$

where $v_{i \alpha \beta}=v_{i \alpha}+j v_{i \beta}$.

Applying (A1) into (8),

$$
\left[\begin{array}{l}
v_{i \alpha} \\
v_{i \beta}
\end{array}\right]=\sqrt{3} e^{-j \pi / 6}\left(\frac{1}{3}\left[\begin{array}{l}
v_{c \alpha} \\
v_{c \beta}
\end{array}\right]+R C \frac{d}{d t}\left[\begin{array}{l}
v_{c \alpha} \\
v_{c \beta}
\end{array}\right]-\frac{R}{n}\left[\begin{array}{l}
i_{s \alpha} \\
i_{s \beta}
\end{array}\right]\right)
$$

can be obtained. Transformation from $\alpha \cdot \beta$ frame to $d \cdot q$ frame can be obtained by using (A3).

$$
v_{i d q}=e^{-j \omega t} v_{i \alpha \beta}
$$

$$
\text { where } v_{i d q}=v_{i d}+j v_{i q}
$$

$$
\begin{array}{r}
v_{i d q}=\sqrt{3} e^{-j \pi / 6}\left(e^{-j \omega t} \frac{v_{c \alpha \beta}}{3}-e^{-j \omega t} \frac{R}{n} i_{s \alpha \beta}\right. \\
\left.+e^{-j \omega t} R C \frac{d\left(e^{j \omega t} v_{c d q}\right)}{d t}\right)
\end{array}
$$

$$
\begin{aligned}
v_{i_{-} d}+j v_{i_{-} q} & =\left(v_{c_{-} d}\left(\frac{1}{2}+\frac{\sqrt{3}}{2} \omega R C\right)+v_{c_{-} q}\left(\frac{1}{2 \sqrt{3}}-\frac{3}{2} \omega R C\right)\right. \\
& -i_{s_{-} d}\left(\frac{3}{2} \frac{R}{n}\right)-i_{s_{-} q}\left(\frac{\sqrt{3}}{2} \frac{R}{n}\right) \\
& \left.+\frac{3}{2} R C \frac{d v_{c_{-} d}}{d t}+\frac{\sqrt{3}}{2} R C \frac{d v_{c_{-} d}}{d t}\right) \\
& +j\left(v_{c_{-} d}\left(-\frac{1}{2 \sqrt{3}}+\frac{3}{2} \omega R C\right)+v_{c_{-} q}\left(\frac{1}{2}+\frac{\sqrt{3}}{2} \omega R C\right)\right. \\
& -i_{s_{-} d}\left(\frac{\sqrt{3}}{2} \frac{R}{n}\right)-i_{s_{-} q}\left(\frac{3}{2} \frac{R}{n}\right) \\
& \left.+\frac{\sqrt{3}}{2} R C \frac{d v_{c_{-} d}}{d t}+\frac{3}{2} R C \frac{d v_{c_{-} d}}{d t}\right) \ldots \ldots .(\mathrm{A} 5)
\end{aligned}
$$

Alper Akdağ (Student Member) received the B.Sc. and M.Sc. degrees in electrical engineering from Middle East Technical University, Ankara, Turkey, and Dr. of Engineering degree from Chiba Institute of Technology, Chiba, Japan, in 1993, 1996, and 2001 , respectively.

Between 1993-1997, he was a Research Assistant in the Electrical and Electronics Engineering Department, Middle East Technical University, and also a part time researcher in the Power Electronics Division, TUBITAK Information Technologies and Electronics Research Institute.

$\mathrm{Mr}$. Akdag is a student member of IEEE and the Institute of Electrical Engineers of Japan.

Susumu Tadakuma (Member) was born in

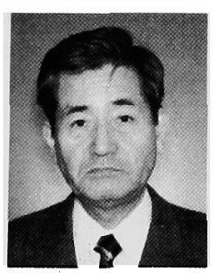
Kumamoto, Japan, on February 5, 1939. $\mathrm{He}$ received the B.Sc. and Dr. of Engineering Degrees from Waseda University, Tokyo, Japan, in 1962 and 1978, respectively.

He joined Toshiba Corporation in 1962 , where he was engaged in power electronics applications to industrial motor drives and high speed transport systems at R\&D Center (1962-1978) and Heavy Apparatus Engineering Laboratory (1979-1994). Since 1995 he has been a Professor of Chiba Institute of Technology, Chiba, Japan.

Dr. Tadakuma is a Fellow, IEEE and a member of IEEJ and SICE, Japan. He served as a Member at Large, IAS Executive Board, IEEE from 1994 to 1997 and Chairman of the IEEE Industry Applications Society Tokyo Chapter from 1995 to 1996. 